\title{
POLÍTICAS REGULATÓRIAS, SUBJETIVIDADE E OS ENTRAVES À DEMOCRACIA NA ESCOLA PÚBLICA BRASILEIRA: contribuições à pesquisa curricular
}

\author{
Sanny S. da Rosa \\ Universidade Municipal de São Caetano do Sul - USCS
}

\begin{abstract}
Resumo
Este ensaio discute os efeitos das políticas regulatórias de educação na organização do trabalho escolar e na construção de novas subjetividades profissionais. Explora os mecanismos de controle e poder da Nova Gestão Pública que, articulados a certos traços conservadores e autoritários de nossa sociedade, configuram o modo peculiar com que professores e gestores têm lidado com esse paradigma de gestão pedagógica e curricular na escola pública brasileira. As questões debatidas neste texto têm origem em pesquisas realizadas em uma rede municipal de ensino do ABC Paulista, cujas características se configuram como microcosmo do tema estudado. Argumenta-se que o espírito competitivo das práticas gerencialistas tende a potencializar os históricos entraves ao princípio da gestão democrática da educação instituído na Constituição Federal de 1988. Não obstante, em meio ao mal-estar provocado pelas contradições desse modelo mas também aos registros de muitos avanços conquistados na educação, é possível vislumbrar espaços de resistência. Considerar esses elementos nas pesquisas curriculares pode ampliar a visão sobre os desafios deste campo frente à mais recente onda conservadora que paira hoje sobre a educação brasileira.
\end{abstract}

Palavras-chave: políticas regulatórias de educação; gerencialismo; subjetividades profissionais; gestão democrática; pesquisa curricular

\begin{abstract}
This essay discusses the effects of education regulatory policies on the school work organization and on the building of new professional subjectivities. It explores the ways in which New Public Management mechanisms of power and control, articulated with the Brazilian conservative and authoritative social features, shapes the peculiar way through which teachers and school managers deal with such a pedagogical and curriculum paradigm in public schools. The issues discussed in this paper are drawn upon researches carried out at a municipal education system of ABC Paulista that might be viewed as a microcosm of such a subject of study. It is argued that the competitive spirit of the managerial practices tends to enhance historical obstacles to the democratic management of education set as a tenet of the 1988 Brazilian Constitution. Nevertheless, amid the unrest generated by the contradictions of this paradigm but also the records of many education breakthrough already achieved there might be a sight for resistance. Considering these elements in curricular research might broaden up the view on the challenges of this field in the face of the latest conservative wave that hovers over Brazilian education today.
\end{abstract}

Keywords: regulatory education policies; managerialism; professional subjectivities; democratic management; curricular research 


\section{Introdução}

Desde que as avaliações de larga escala se consolidaram como cultura nos meios educacionais, a busca pela elevação dos indicadores de desempenho passou a ocupar lugar central na rotina escolar e tornou-se um dos principais fatores de intensificação do trabalho docente. Na onda das mudanças do papel do Estado e das reformas globais de educação iniciadas nas últimas décadas do século XX, o espírito concorrencial da Nova Gestão Pública (NGP) não produziu apenas efeitos objetivos nas formas de organização e administração da escola e na condução do trabalho pedagógico. Transformações subjetivas e nas relações entre pares foram operadas como epifenômeno desse espírito, concorrendo para a redefinição da identidade dos profissionais da educação.

A concepção empresarial de administração escolar, de viés neoliberal, consistentemente criticada por autores brasileiros ao longo das últimas décadas (ARROYO, 1979; FÉLIX, 1985; PARO, 2016), hoje se concretiza em estratégias tidas como mais eficazes para a obtenção de melhores resultados, servindo de lastro às "boas práticas" de gestão. Capitaneadas pelos critérios das avaliações, as políticas regulatórias do currículo não apenas direcionam o que ensinar, como prescrevem o modelo didático a ser seguido nas salas de aula, restringindo a autonomia das escolas e dos docentes.

Na esteira desse movimento, as formações inicial e continuada de professores passaram a ser igualmente reguladas, monitoradas e auditadas, prática que abriu boas oportunidades de negócios para os reformadores empresariais da educação (FREITAS, 2014; HELOANI, 2018). Com frequência cada vez maior, escolas públicas têm sido surpreendidas com pacotes de "soluções" pedagógicas e de gestão produzidas por organizações filantrópicas e/ou empresas privadas, contratadas, principalmente, pelas redes municipais de ensino (BALL, 2007; BALL, MAGUIRE, BRAUN, 2012; ANDERSON, 2017; ADRIÃO, et. al., 2012, 2018; PERONI, 2018).

Apresentados como parceiros imbuídos do propósito de melhorar a qualidade da educação pública, a tutela desses consultores converte gestores e professores em executores/multiplicadores de programas - eufemisticamente chamados de "propostas" alheios à história, aos contextos locais e às necessidades da escola. "Soluções" padronizadas de ensino ignoram o processo de aprendizagem dos alunos, que só ocorre na concretude das experiências vividas nos espaços/tempos de cada unidade escolar; e as "modernas" estratégias de gestão desprezam não apenas os profissionais, como a cultura e a história das instituições de ensino.

A ideologia pragmática, utilitarista e individualista do modelo gerencial de administração pública tem logrado formar subjetividades profissionais sensíveis às auditorias externas, orientadas por critérios fixos de qualidade que se traduzem em indicadores quantitativos, quando não meramente contábeis. Ao cooptar as consciências, o gerencialismo redefine a noção de profissionalismo, que já não guarda relação com o valor ético e político do ato educativo, mas com a performance da escola e de seus profissionais (BALL, 2005; LIMA; 2001, ANDERSON, 2017). O (relativo) êxito desse projeto, adotado 
em escala global, decorre do seu poder de modificar a natureza e o sentido da educação escolar.

As mudanças pretendidas pelo paradigma gerencial da NGP no Brasil, porém, não ocorrem sem (alguma) resistência. E não apenas porque se chocam com a tradição iluminista e republicana que deu forma à escola moderna e reservou lugar de prestígio social e autoridade intelectual aos professores. Há muito que esse status vem sendo perdido pelos profissionais das escolas públicas brasileiras. Mas porque as contradições dos princípios autodeclarados desse modelo produzem tensões, conflitos e paradoxos que colocam à prova as suas próprias ambições e provocam um clima de mal-estar hoje vivido nas escolas.

Diante desse cenário, o objetivo deste ensaio é explorar alguns efeitos produzidos pela lógica instrumental de educação e discutir como os mecanismos gerenciais de controle e poder potencializam os históricos entraves ao princípio da gestão democrática da educação e à construção de relações mais democráticas na escola. Entende-se que a consideração desses elementos nas pesquisas curriculares pode ampliar o entendimento dos desafios deste campo frente à mais recente escalada conservadora que ronda as escolas públicas brasileiras.

Para tanto, a primeira seção deste texto explicita as premissas e os mecanismos de controle e poder da NGP para, em seguida, perscrutar os efeitos (objetivos e subjetivos) desse modelo de gestão nos meios educacionais. O terceiro e último tópico analisa, pelas lentes de um caso particular, como a lógica competitiva do modelo gerencial se combina e se hibridiza com os traços conservadores e autoritários da sociedade brasileira, criando novos obstáculos à construção de relações democráticas na escola pública; mas também como, em meio às suas próprias contradições, abrem-se brechas para potenciais movimentos de resistência.

\section{Mecanismos de controle e poder da Nova Gestão Pública}

O modelo gerencial de administração pública, adotado com o Plano Diretor de Reforma do Aparelho de Estado, aprovado em 1995, no governo de Fernando Henrique Cardoso, visava explicitamente "criar condições para a reconstrução da administração pública em bases modernas e racionais” (BRASIL, 1995, p. 6). Com a reforma pretendia-se superar tanto os vícios do patrimonialismo, marcado pelo clientelismo e pelo nepotismo praticados desde tempos coloniais, como a rigidez hierárquica do modelo racional burocrático implementado a partir dos anos 1930.

A reforma dos aparelhos de Estado não se reduzia à adoção de métodos mais modernos e racionais de administração, mas operava mudanças conceituais importantes das noções de público e estatal, abrindo espaços cada vez maiores para a participação dos interesses privados na formulação e condução das políticas públicas do país. 
O chamado setor público não-estatal considerado capaz de atender às demandas dos diversos agentes (...) exigiria um tipo de capacidade gerencial específica, diferente da administração pública estatal anterior à Reforma. Essa capacidade gerencial da esfera social seria o que, genericamente, se define como gestão. Uma das características da "gestão" seria ultrapassar a dicotomia entre planejamento e execução, agora concebidos como flexíveis e partes de um mesmo processo. Tal seria o sentido da "administração por resultados", que integraria avaliação e resultado ao próprio processo de decisão e execução (GANDINI; RISCAL, 2008, p. 55).

A expectativa e o entusiasmo do então presidente da república de colocar o país nos trilhos do desenvolvimento e da economia globalizada, em ascensão nos anos 1990, ficam nítidos no tom otimista deste trecho introdutório do Plano de sua própria autoria:

É preciso, agora, dar um salto adiante, no sentido de uma administração pública que chamaria de "gerencial", baseada em conceitos atuais de administração e eficiência, voltada para o controle dos resultados e descentralizada para poder chegar ao cidadão, que, numa sociedade democrática, é quem dá legitimidade às instituições e que, portanto, se torna "cliente privilegiado" dos serviços prestados pelo Estado (BRASIL, 1995, p. 7, grifos nossos).

Com esse giro conceitual, o Plano apostava, antes de tudo, na mudança de mentalidade dos servidores públicos a respeito do seu papel. Embora procurando distinguir-se das fórmulas neoliberais ${ }^{1}$, em seu conjunto, o espírito do Plano Diretor alinhava-se aos princípios e valores de administração praticados na iniciativa privada. Pautava-se pela premissa de que, em um ambiente mais competitivo e movido por recompensas, toda a engrenagem administrativa funcionaria de modo mais eficiente, ágil e eficaz. Falava-se em reorganização da máquina estatal, em qualidade e produtividade e prometia-se uma “verdadeira profissionalização do servidor”. Nas palavras de FHC:

Se quisermos avançar na adoção de formas modernas de gestão pública, é imprescindível, também, que os servidores passem a ter uma nova visão de seu papel, pois é no dia a dia do exercício das funções públicas que a mais profunda e verdadeira reforma vai realizar-se (BRASIL, 1995, p. 7).

Com efeito, a concretização da nova concepção de público e estatal dependia da assimilação subjetiva do novo papel pelos funcionários públicos, agora entendidos como "prestadores de serviços” a “clientes privilegiados”. O grande equívoco dessa aposta foi acreditar na possibilidade de compatibilizar duas noções intrinsecamente antagônicas, pois, ou bem o servidor se guia pelo valor da coisa (res) pública como direito do cidadão, ou passa a vê-lo como um “cliente privilegiado” de cuja satisfação pode extrair benefícios particulares.

Assumir um ou outro papel implica posicionar-se, subjetivamente, em lugares distintos, uma vez que as representações associadas a um e outro entendimento direcionam, 
em sentidos opostos, a construção da identidade profissional do servidor público. E como as identidades profissionais são sempre construídas pelo olhar do outro (DUBAR, 2006; 2012), em meio a mecanismos de controle e poder, resta elucidar quais são e como operam esses mecanismos na administração de tipo gerencial.

Analisando o paradigma pós-fordista de administração, base da ideologia gerencialista, Heloani (2018) observa que o sistema vertical e hierárquico da relação capital-trabalho, sustentado em ordens, foi substituído pelo estabelecimento de regras às quais busca-se a adesão dos trabalhadores. A internalização dessas regras, de acordo com o autor, constitui uma estratégia bem mais sofisticada de enunciação do poder, uma vez que opera sobre o inconsciente no processo de identificação do indivíduo com os valores da organização. Com isso, dilui-se o conflito trabalho-capital, o que possibilita conceder maior "autonomia" ao trabalhador na exata medida em que lhe são atribuídas novas responsabilidades e demandadas outras formas de qualificação para o trabalho.

Por sintetizar o funcionamento de um complexo e sutil processo de captura das consciências, que arrasta o indivíduo para a condição psicológica necessária ao êxito dessa empreita ideológica, vale reproduzir o raciocínio do autor sobre o funcionamento do que ele chama de "gestão do inconsciente".

Do ponto de vista da gestão do inconsciente, esse projeto implica incentivar o nível de fusão afetiva com a "empresa-mãe” e sofisticar os códigos de identificação com a "empresa-protetora”. Para obter essa identificação, a gestão dos códigos deverá atingir o processo de significação, ou melhor, o plano das representações. Os significados serão administrados para implicitamente difundir a subordinação do trabalho ao capital, a qual não deve ser apenas formal ou rítmica, mas afetiva, subjetiva e psicológica. (...) Ao largo da autonomia concedida para certas funções, o capital difunde no nível do inconsciente da organização, todo um processo de controle para inibir a maturidade política do trabalho (HELOANI, 2018, p. 116, grifos do autor).

É importante destacar e traduzir cada um desses mecanismos: (1) incentivo à fusão afetiva do trabalhador com a empresa com vistas à sua identificação com os valores da organização; (2) construção de novas representações (significações) sobre o lugar/papel do trabalho na relação com o capital; (3) subordinação subjetiva (psicológica) do trabalhador aos termos dessa nova relação; (4) estabelecimento de um sistema controle que tem por base a adesão (inconsciente) do trabalhador a um pacto (tácito) pelo qual certos benefícios (pecuniários/simbólicos) podem ser auferidos contra a entrega dos resultados (metas) definidos pela organização.

A maior perversidade da feição neoliberal da relação capital/trabalho é que nela 0 fenômeno da alienação não se restringe à venda da força de trabalho no mercado capitalista, conforme a clássica explicação marxista. Nessa dinâmica intersubjetiva, a moeda de troca é a consciência do trabalhador. O fenômeno da alienação é, assim, camuflado pela (pseudo) autonomia a ele concedida nos termos de um pacto de servidão voluntária ${ }^{2}$ à lógica 
pragmática dessa nova relação. Espera-se que o trabalhador “vista a camiseta” do projeto ao qual se mantém aprisionado e em estado de minoridade política.

Nessa teia, os vínculos do sujeito com o objeto de seu trabalho se veem erodidos pelas sedutoras promessas de recompensa (pecuniárias e simbólicas) pelos esforços empreendidos. Eis como se dá e triunfa o fenômeno da alienação em tempos neoliberais: ao estabelecer uma clivagem entre a subjetividade do sujeito e o produto de seu trabalho, ele não mais se reconhece neste último como autor. Nas palavras de Marilena Chauí (2012, p. 93), passa a vê-lo como "coisas prontas que parecem existir por si mesmas. Em suma, o trabalhador não as percebe como objetivação de sua subjetividade humana.”

Num mundo em que o único caminho para o "sucesso" é o desempenho individual, a alienação do trabalhador público é nefasta para a democracia. Com a dissolução das referências ao interesse comum, seu trabalho é “dessimbolizado”, e ele passa a ser o portador da mensagem de que os direitos do cidadão podem ser reivindicados como bens privados por “clientes privilegiados”. Com o esvaziamento das relações na esfera política,

Tudo se reduz ao exercício pragmático do controle e da influência. A nova concepção de democracia torna-se a última instância de legitimação retórica, desaparecendo qualquer significação transcendental de orientação para a sociedade ou de constituição de uma identidade coletiva. O fim da capacidade de orientação normativa geral acontece no momento em que se liberam todas as forças transformadoras das técnicas, acabando as sociedades por se fundir elas mesmas com essas técnicas ou com a gestão de seus resultados. (DUPAS, 2003, p. 59)

Em tal ambiente, transformações importantes na identidade dos servidores públicos tendem a ocorrer por efeito das marcas subjetivas operadas pelos mecanismos gerenciais de controle e poder. No caso brasileiro, tais marcas se combinam com outras inscrições, de fortes traços autoritários e conservadores que, em grande medida, configuram o modo peculiar com que os profissionais de educação passam a lidar com o paradigma da NGP. A maneira como essas duas mentalidades se cruzam no campo da formulação das políticas educacionais brasileiras tem chamado a atenção de alguns estudiosos (LIMA; GANDIN, 2017; ROSA, 2012). Interessa, neste trabalho, analisar como elas hibridizam nas práticas pedagógicas e curriculares e na subjetividade dos educadores.

\section{Efeitos subjetivos das práticas gerencialistas nos meios educacionais}

Considerando que os sistemas públicos de ensino estão cada vez mais contaminados pelos ideais e práticas do mundo corporativo, pode-se dizer que os mecanismos de controle e poder do modelo gerencial têm obtido certo êxito na formação de subjetividades, pois estes já habitam o plano das representações dos profissionais de educação. 
A incorporação do vocabulário empresarial ao léxico pedagógico talvez seja um dos sintomas mais evidentes da (ingênua) adesão de parcela significativa dessa categoria às regras do jogo. Mas não só. A aceitação pacífica da tutela e monitoramento do trabalho de sala de aula por parte de consultores "especializados”, a convivência "natural” com a cultura de auditoria, a inclinação a atender as demandas e expectativas externas, entre outros sinais, são indicativos de uma certa disposição dos profissionais de educação de contribuírem para o sucesso desse projeto que, em muitos casos, até é visto com bons olhos.

A introjeção dos princípios e valores da NGP nos meios educacionais foi turbinada com o advento das avaliações de larga escala, subsumido na reforma do Aparelho de Estado de 1995. Como se sabe, os ciclos nacionais de avaliação foram instituídos no Brasil com o propósito de melhorar a qualidade da educação básica, seguindo diretrizes dos organismos internacionais, particularmente, as da Organização para Cooperação e Desenvolvimento Econômico (OCDE). Na medida em que pautaram o currículo e, como desdobramento, induziram políticas de bonificação por desempenho, as avaliações se converteram no eixo central em torno do qual as escolas se organizam. Com isso, as auditorias externas transformaram-se na bússola norteadora das decisões consideradas verdadeiramente importantes para melhorar a performance dos sistemas de educação e das unidades de ensino.

Assim, efeitos objetivos das políticas regulatórias se fizeram sentir no dia a dia das escolas: o calendário escolar passou a ser definido em função dos ciclos avaliativos; a distribuição da carga horária entre os componentes curriculares privilegiou aqueles com maior peso nas avaliações de larga escala, como a língua materna e a matemática; a seleção e a ordem de apresentação dos conteúdos, como também a escolha das estratégias didáticas levaram em conta o desenvolvimento das competências e habilidades valorizadas nos testes padronizados. Estes são alguns exemplos da subordinação da escola à lógica em vigor.

Subsidiariamente, critérios externos de julgamento também são mantidos no radar dos que definem as estratégias para otimizar a "produtividade" das escolas, tais como: as pautas formativas dos docentes; as atividades dos horários de trabalho coletivo na escola; os critérios de agrupamento dos alunos e alocação de professores; o destino dos alunos com baixo desempenho escolar, problemas de comportamento ou baixa frequência; e, ainda, ações consideradas necessárias para compatibilizar políticas contraditórias entre si, como, por exemplo, as de avaliação e as de inclusão.

Tamanho esforço, no entanto, não deve ser interpretado como sinal de uma adesão autêntica dos profissionais de educação aos princípios e regras do modelo gerencial. Essa seria uma leitura limitada e parcial do fenômeno, pois as contradições e paradoxos engendrados pelas políticas regulatórias concorrem para a emergência do calcanhar de Aquiles desse modelo de gestão: a qualidade de ensino.

Pressionados pela expectativa de reconhecimento, gestores e professores são induzidos a incluir no cálculo dos processos decisórios o impacto de suas escolhas nos indicadores da escola, relegando a segundo plano as necessidades da escola. Nesse ambiente, são consideradas "boas práticas" (de gestão e curriculares) aquelas que revelarem maior 
potencial para alcançar as metas externamente estabelecidas, mesmo que, para isso, seja necessário inverter a ordem de prioridades pedagógicas, dar maior atenção aos meios do que aos fins educativos e, até mesmo, lançar mão de procedimentos pouco ortodoxos para que a escola e os sistemas de ensino "saiam bem na fotografia".

Em suma, face a muitas pressões, arranjos acabam sendo feitos para que os resultados correspondam, ao menos em aparência, às expectativas do sistema. Um deles é adiantar conteúdos que, em outras condições, seriam trabalhados em sequências didáticas que respeitariam a lógica dos conceitos e o ritmo de aprendizagem dos estudantes. Outro é encontrar formas para evitar que os alunos "mais fracos" - ou os “de inclusão" - estejam presentes nos dias de provas. Ou, ainda, treinar alunos para os testes padronizados. Situações como essas são frequentes nas escolas e já foram relatadas em diversos estudos (BONAMINO; SOUZA, 2012; CHIRINÉIA; BRANDÃO, 2015; BALL, MAGUIRE, BRAUN, 2012; ANDERSON, 2017).

[...] evidências nacionais e internacionais mostram que principalmente o uso de resultados das avaliações da terceira geração para informar iniciativas de responsabilização forte pode envolver riscos para o currículo escolar. Um deles é a situação conhecida como ensinar para o teste, que ocorre quando os professores concentram seus esforços preferencialmente nos tópicos que são avaliados e desconsideram aspectos importantes do currículo, inclusive de caráter não cognitivo. (BONAMINO; SOUZA, 2012, p. 383, grifos das autoras).

Arranjos como esses traduzem uma prática que a linguagem comum define melhor do que a acadêmica: a de "tapar o sol com a peneira". Tais práticas podem ser interpretadas como reação ou mecanismos de defesa acionados contra as ameaças à reputação de pessoas e instituições. Mas também como proteção à situação de vulnerabilidade no trabalho, visto que em grande parte dos municípios brasileiros os cargos de gestão continuam a ser ocupados à moda patrimonialista, isto é, por indicação política (DOURADO, 2001; DRABACH, 2013; MARTINS; MACHADO; BRAVO, 2018). A criatividade empregada pelos profissionais da escola para lidar com as pressões concorre para um jogo de faz de conta que camufla e distorce a realidade, constituindo-se, por isso mesmo, em armadilha para a qualidade tão almejada.

Esse processo se intensificou à medida que a finalidade das avaliações visou responsabilizar professores e escolas pelos resultados, afetando o currículo e a dinâmica das relações escolares. Considerando esse movimento em um continuum, Bonamino e Sousa (2012) identificaram três gerações de avaliação de larga escala no Brasil: as de primeira geração, inauguradas com o SAEB (Sistema de Avaliação da Educação Básica), não traziam consequências diretas para as unidades escolares, pois, sendo amostrais, não permitiam medir a evolução do desempenho individual de alunos e escolas. Mas, com a introdução do IDEB (Indicador de Desenvolvimento da Educação Básica), seguiram-se as políticas de segunda geração (low stakes) ou de "responsabilização branda"; e as de terceira (high stakes) ou de "responsabilização forte”. 
A publicização dos resultados permitiu a construção de rankings pela mídia, expondo escolas e professores a julgamento público. Vale observar que a tradução literal dessas denominações revela de modo mais preciso a intencionalidade de tais políticas: low stakes significa "aposta baixa”, que mira efeitos "apenas” (!) simbólicos; e high stakes, "aposta alta”, cujas consequências são tidas como mais “sérias”. Essas classificações minimizam a importância dos efeitos simbólicos (subjetivos) das políticas regulatórias e reforçam a crença de que a qualidade almejada depende mais do impacto que tiverem no bolso de professores e gestores do que do seu engajamento autêntico com o trabalho educativo.

A lógica econômica (ou contábil?) desse paradigma de gestão pública contribui para o esvaziamento do sentido pedagógico, ético e político da educação escolar. Os efeitos simbólicos e subjetivos desse esvaziamento são mais danosos para a qualidade do ensino do que os possíveis constrangimentos advindos da exposição pública dos (maus) resultados nas avaliações. Ao transformar a escola em um ambiente cada vez mais competitivo e pragmático, a ideologia gerencialista despersonaliza o trabalho docente, aniquila o caráter artesanal do ensino e desconecta o ato educativo de seu valor intrinsecamente humano.

Em uma perspectiva republicana, o valor intrínseco do trabalho educativo identificavase com a capacidade da escola de ampliar os horizontes de compreensão do mundo dos alunos por meio do conhecimento e do pensamento crítico e de formar personalidades sensíveis e aptas ao convívio democrático através de interações humanas respeitosas e solidárias. Por esse entendimento, o conjunto de experiências escolares visa o bem comum, o que pressupõe conceber a educação como coisa (res) pública a que todos têm direito para que possam usufruir de e contribuir para o patrimônio cultural da humanidade e partilhar de uma vida social digna. Nessa perspectiva, à figura do professor associam-se representações que lhe conferem posição de autoria e autoridade moral perante os alunos, lastreada no reconhecimento de seus saberes e no valor social e humano do seu trabalho.

$\mathrm{Na}$ perspectiva da racionalidade instrumental, ao contrário, a educação escolar é reduzida à mercadoria com valor de troca em um mercado de trabalho cada vez mais fluido, imprevisível e desregulamentado, no qual os indivíduos são lançados a competir. Para atender as alegadas exigências desse mercado, a escola é premida a perseguir um currículo pré-moldado ao design das avaliações externas. Não é outro o espírito que preside a Base Nacional Comum Curricular (BNCC), cuidadosamente arquitetada por representantes dos interesses privados (AVELAR, BALL, 2017), para que as habilidades descritas e codificadas, desde a Educação Infantil até o Ensino Médio, facilitem a sua conversão em testes padronizados. Nessa corrida, o "sucesso" é medido por critérios meritocráticos aos quais é esperado que cada um se ajuste.

À tal entendimento sobre o papel da educação associa-se representações que apequenam o lugar social do professor e obscurecem o sentido político da educação escolar. Monitorado a partir do exterior, o caráter artesanal e relacional do "ofício de mestre" (ARROYO, 2009) perde terreno para técnicas pré-fabricadas de ensinar e o valor do conhecimento é calculado pela razão direta de sua utilidade prática. Com isso, os tempos de formação (PONCE, 2016), tempos de ensinar, aprender e conviver, são atropelados pelas urgências de um projeto abstrato, voltado para um futuro idealizado e incerto. Mais grave 
que isso, os tempos de escola são transferidos (alienados) para o projeto do Outro (do mercado!), com o que se desconectam da subjetividade dos sujeitos.

O fenômeno da alienação se configura, assim, como o efeito mais perverso da lógica instrumental e pragmática que modifica o sentido da educação, as relações dentro da escola e atinge em cheio a saúde (física e psíquica) do trabalhador:

Sob tais condições de alienação, o que se tem verificado é que tal fenômeno está relacionado ao estranhamento, cujas saídas individuais manifestam-se sob a forma de estratégias defensivas de caráter patológico, com implicações nas relações sociais no trabalho e, consequentemente, na saúde do trabalhador (HELOANI, 2018, p.191)

Autores como Sennet (1999), Ball (2005, 2012), Anderson (2017) já mostraram como as reformas orientadas pelas crenças e fórmulas neoliberais reformam também a relação dos profissionais com o seu trabalho, forjando um outro entendimento de profissionalismo. $\mathrm{O}$ texto de Stephen Ball, intitulado Profissionalismo, Gerencialismo e Performatividade, tem sido bastante utilizado pelos que discutem as tecnologias empregadas nas reformas. Mas, menor ênfase tem sido dada ao alerta do autor de que essas tecnologias não mudam só o que fazemos, mas o significado do que fazemos, a forma como interagimos com os outros e, portanto, "aquilo que somos, aquilo que poderíamos vir a ser (BALL, 2005, p. 546, grifos nossos). Isso porque na lógica que preside as reformas,

A eficácia prevalece sobre a ética; a ordem sobre a ambivalência (...) Novos papéis e subjetividades são produzidos à medida que os professores são transformados em produtores/fornecedores, empresários da educação e administradores, e ficam sujeitos à avaliação e análise periódicas e a comparações de desempenho (BALL, 2005, p. 548).

Segundo Richard Sennet, sociólogo e historiador norte-americano, esse ambiente é propício para a “corrosão do caráter”, pois dissolve os laços de confiança e de compromisso mútuo. Para esse estudioso das novas relações de trabalho no estágio neoliberal do capitalismo, a senha de sobrevivência em um mundo organizado em torno de metas de curto prazo e retornos rápidos é "não se comprometer e não se sacrificar" (SENNET, 1999, p.25).

Esse espírito bateu às portas da escola, gerando um clima de competição, medo, desconfiança e, o que é pior, de irresponsabilidade. Em artigo em que discute a privatização das subjetividades na Nova Gestão Pública (NGP), Gary Anderson alerta para a importante diferença entre responsabilidade e prestação de contas (accountability): "Enquanto a responsabilidade profissional é centrada no julgamento e na ética do profissional, a prestação de contas é centrada na adequação profissional aos indicadores externos impostos a ele.” (ANDERSON, 2017, p. 618, grifo meu).

No mesmo texto, o autor descreve como, em escolas públicas norte-americanas geridas pelo espírito empreendedor e competitivo das startups, os gestores são pressionados a 
recrutar os "bons” professores em outras escolas e a rejeitar alunos que ameaçam reduzir os indicadores de desempenho. De onde conclui: "os sistemas de prestação de contas que presenciamos pressionam o 'novo' profissional a se comportar de forma irresponsável” (p. 619) - o que compromete o espírito que deveria presidir as práticas nos sistemas públicos de ensino.

O intento de aumentar a produtividade das escolas via accountability pode até obter êxito a curto prazo, mas ao custo de, ao longo do tempo, corroer os vínculos de confiança indispensáveis à sustentação de projetos genuinamente educativos. Em ambientes instáveis, valores como lealdade e confiança se dissolvem em meio a laços sociais superficiais e passageiros. É plausível, então, conjecturar que a busca de melhoria da qualidade da educação por meio de estratégias gerenciais é um tiro que tende a sair pela culatra. Isso porque escapa aos estrategistas de tais políticas que, diferente de outros "ramos de negócio”, educação é projeto de longo prazo que pressupõe compromisso coletivo em torno de objetivos comuns.

Essas falhas e contradições não são captadas nas aferições de larga escala; não obstante, constituem armadilhas para um projeto que, em grande parte, sobrevive de suas próprias ilusões. No caso brasileiro, os mecanismos gerenciais de controle e poder convivem com entraves históricos ao exercício da democracia e, por conseguinte, comprometem o princípio da gestão democrática conquistado na legislação educacional vigente. É o que procurarei argumentar no próximo tópico, apontando algumas raízes dessas dificuldades com exemplos extraídos de pesquisas realizadas em um município da região do Grande ABC Paulista.

\section{Entraves à gestão democrática: um tema recorrente pelas lentes de um caso particular}

Proclamado como princípio da educação na Constituição Federal de 1988 e na Lei de Diretrizes e Bases da Educação Brasileira (Lei 9394/96), e evocado, desde então, por representantes dos mais variados matizes ideológicos, a gestão democrática é um conceito escorregadio que permanece incompreendido e pouco praticado. Um trecho do discurso de Luiz Antônio Cunha, proferido em setembro de 1986 na IV Conferência Brasileira de Educação, em Goiânia, sintetiza o entendimento de “democrático" reivindicado pelo movimento dos educadores então engajados com a redemocratização do ensino e da sociedade brasileira:

O ensino democrático não é só aquele que permite o acesso de todos que o procuram, mas, também, oferece a qualidade que não pode ser privilégio de minorias econômicas e sociais. O ensino democrático é aquele que, sendo estatal, não está subordinado ao mandonismo de castas burocráticas, nem sujeito às oscilações dos administradores do momento. Tem, isto sim, currículo, condições de ingresso, promoção e certificação, bem como métodos e materiais 
discutidos amplamente com a sociedade, de modo que os interesses da maioria, em termos pedagógicos, sejam efetivamente respeitados. O ensino democrático é, também, aquele cuja gestão é exercida pelos interessados, seja indiretamente, pela intermediação do Estado (que precisamos fazer democrático), seja diretamente, pelo princípio da representação e da administração colegiada (CUNHA, 1987, p. 6, grifos do autor).

Com efeito, gestão democrática não é um conceito genérico que possa ser descolado da experiência concreta de cada sociedade no processo de construção da democracia como forma de governo e como princípio regulador das relações sociais. No campo da Educação, dispomos de farta literatura sobre o tema da gestão democrática que, em geral, também se refere à nossa dificuldade de realizá-la. Alguns desses estudos buscam encontrar em tempos mais remotos, ou em passagens mais recentes vida social e política brasileira, elementos que expliquem a fragilidade e/ou a incipiência de nossa experiência de democracia (MENDONÇA, 2000; CURY, 2002; GANDINI, RISCAL, 2008; DRABACH; 2009, 2016).

A promiscuidade entre as esferas da vida pública e privada tem sido apontada, de forma recorrente, como um dos fatores determinantes dessa fragilidade, tema que foi bastante explorado nas obras clássicas de Raimundo Faoro (1975) e Sérgio Buarque de Hollanda (1963) sobre a formação da sociedade e do Estado brasileiros. A prática social e política, em que interesses particulares prevalecem sobre o bem comum na administração e condução dos assuntos de Estado foi denominada pelo sociólogo alemão, Max Weber (1864-1920), de patrimonialismo. Lilia Moritz Schwarcz, em seu recente livro Sobre o Autoritarismo Brasileiro, se refere a esse conceito de forma clara e didática, elucidando que o patrimonialismo é:

[...] o resultado da relação viciada que se estabelece entre a sociedade e o Estado, quando o bem público é apropriado privadamente. Ou, dito de outra maneira, trata-se do entendimento, equivocado, de que o Estado é bem pessoal, “patrimônio” de quem detém o poder (SCHWARCS, 2019, p. 65).

Dentre as razões pelas quais o patrimonialismo, o autoritarismo e o racismo prosperaram tanto no Brasil, a autora dá destaque ao sistema escravocrata que se estabeleceu no processo de formação da sociedade brasileira, marcando profundamente os “costumes da terra” ao longo de mais de três séculos.

Não se escapava da escravidão. Aliás, no caso brasileiro, de tão disseminada ela deixou de ser privilégio de senhores de engenho. Padres, militares, funcionários públicos, artesãos, taverneiros, comerciantes, pequenos lavradores, grandes proprietários, a população mais pobre e até libertos possuíam cativos. E, sendo assim, a escravidão foi bem mais que um sistema econômico: ela moldou condutas, definiu desigualdades sociais, fez de raça e cor marcadores de diferenças fundamentais, ordenou etiquetas de mando e obediência, e criou uma sociedade condicionada pelo paternalismo e por uma hierarquia muito restrita (SCHWARCS, 2019, p. 27-28). 
Com tal passado, o Estado brasileiro pouco se identificou com a concepção republicana alicerçada em um ordenamento jurídico que expresse a soberania popular. Ao contrário, as ações do poder público no Brasil, em geral, não se restringem aos limites da Lei, mas se movem por interesses das elites patrimoniais que se perpetuam no poder por força de relações sociais de compadrio, de caráter clientelista e, em muitos momentos de nossa história, sustentadas no apoio direto ou indireto dos militares.

Não é preciso mais do que acompanhar, mesmo que superficialmente, as notícias diárias que hoje nos chegam na palma da mão, para constatar que essa é uma herança da qual ainda estamos por nos libertar. Após inventariar, com nomes e sobrenomes, a persistência de uma estrutura política enraizada no poder de clãs familiares e de grandes proprietários de terra, com assento garantido no Congresso Nacional - inclusive nas eleições de 2018 - a autora conclui que:

Essa é uma forma autoritária e personalista de lidar com o Estado, como se ele não passasse de uma generosa família, cujo guia é um grande pai, que detém o controle da lei, é bondoso com seus aliados, mas severo com seus oponentes, os quais são entendidos como inimigos (SCHWARCS, 2019, p.87).

Cabe assinalar, neste ponto, que uma sociedade acostumada a lidar com o Estado como se fosse um "pai severo" (e punitivo) tende a ceder mais facilmente a mecanismos de controle e poder que se valem de estratégias afetivas (prêmios, recompensas) para conquistar a adesão dos sujeitos aos propósitos do projeto de uma "mãe-protetora" (HELOANI, 2018). Proponho pensar que a combinação de tais representações (inconscientes) podem ajudar a compreender o modo peculiar com que os profissionais de educação têm lidado com o paradigma da NGP em nossas escolas públicas. Para desenvolver esse raciocínio, utilizarei pistas extraídas de pesquisa realizada em três escolas de um município que é um microcosmo da sociedade brasileira.

Emancipada apenas em 1948, São Caetano do Sul (SCS) é uma cidade jovem; mas, o povoamento da região, originalmente conhecida como Tijucuçu, teve início no século XVI, com a vila de Santo André da Borda do Campo de Piratininga. Encontramos na história do município traços comuns à constituição da sociedade brasileira como um todo: primeiro, foi área de fazendas de jesuítas, doadas posteriormente a monges beneditinos, onde trabalhavam populações indígenas e de origem africana escravizadas. Com a Lei do Ventre Livre, a fazenda São Caetano foi dividida em lotes, vendidos a imigrantes italianos que ali se estabeleceram, no final do século XIX, em busca de oportunidades de trabalho (MARTINS, 2002).

O desenvolvimento industrial dos setores automobilístico, metalúrgico e químico atraiu para a região do ABC Paulista, a partir dos anos 1950, populações de outras regiões do país, principalmente, do nordeste. No final dos anos 1970 e nos anos 1980, foi palco de intensos movimentos sindicais, mas sua população sempre elegeu representantes de perfil conservador ${ }^{3}$. Embora tenha obtido o $1^{\circ}$ lugar no IDHM/2010 (Índice de Desenvolvimento 
Humano por Município (IDH-M), a desigualdade social é perceptível a olho nu: nas regiões do Rio dos Meninos, córrego que marca a divisa com São Bernardo do Campo e São Paulo, e do Rio Tamanduateí, que faz fronteira com Santo André, vive uma população vulnerável que contrasta com os residentes de classes média e alta do bairro Barcelona, um dos mais tradicionais da cidade.

Atualmente, SCS possui cerca 150 mil habitantes que vivem nos limites de apenas 15 $\mathrm{km}^{2}$ (FUNDAÇÃO SEADE, 2017). Uma frase comumente utilizada pelos munícipes caracteriza o clima de convivência na cidade: “Aqui todo mundo se conhece”. Destacada dos contextos de fala, a frase poderia até sugerir condições favoráveis à convivência democrática, mas o tom com que geralmente é enunciada não confirma a primeira impressão. Em diferentes ambientes e situações prevalece um clima de cautela que inibe o diálogo e o debate franco de ideias. Em parte, isso explica por que o município é considerado como o mais centralizador da região e o que menos cria possibilidades de participação da comunidade na vida das escolas. (GARCIA et al, 2015).

A rede municipal de ensino ${ }^{4}$ conta com apenas 20 escolas de Ensino Fundamental (EMEFs) e é descrita no site da Prefeitura como "referência nacional no ensino público de qualidade, com índices de escolaridade comparáveis a de países de Primeiro Mundo”. Tal status se deve tanto à origem socioeconômica dos alunos, predominantemente de classe média, como ao controle rigoroso que a administração local exerce sobre suas escolas. Com tais características, São Caetano do Sul ostenta os melhores índices do IDEB entre os municípios da região ${ }^{5}$.

Foi nesse contexto que, por demanda de profissionais ${ }^{6}$ da rede, um projeto de pesquisa colaborativa (IBIAPINA, 2008) foi desenvolvido em três escolas de ensino fundamental de 2016 a 2018, com o propósito de desencadear um processo de reflexão, com professores e gestores, sobre as condições de possibilidade de uma gestão pedagógica em bases democráticas. Os processos e resultados da pesquisa foram discutidos em outro trabalho (ROSA et al, 2018). Pretende-se, aqui, explorar os traços do ambiente em meio ao qual esses profissionais desenvolvem o seu trabalho.

Alguns desses traços já foram mencionados, como a centralização das decisões no interior de uma estrutura fortemente verticalizada, na qual as relações de poder se sustentam na sensação de constante vigilância. Em tais condições, os (bons) resultados nas avaliações externas representam oportunidade de extração de dividendos políticos para os grupos que se revezam no poder. Os depoimentos obtidos no estudo de Umemura (2018), que tratou do papel da coordenação pedagógica nos processos formativos na escola, são ilustrativos do quanto esse clima interfere na organização do tempo, no currículo e na qualidade do trabalho escolar.

A educação vive muito em busca do resultado: 'você tem que fazer esse projeto pra ontem, porque ele tem que ser publicado, tem que mostrar para alguém'; ou então, 'a prova tem que ter a pontuação " $x$ ” $e$ o percentual de alunos aprovados tem que ser esse...' 
O currículo também parece que não foi muito bem pensado; você joga uma quantidade absurda de conteúdos por trimestre, você não tenta equilibrar os conteúdos ao longo do ano; você joga num e o outro fica mais vazio no final...e assim vai.

A educação vai seguindo com o esforço do profissional, que é o professor. As coisas já vêm prontas. Não que não tenha projetos bons, as avaliações que vieram de fora são boas, mas sempre dá para aprimorar. E vem de fora e para. Não tem processo de continuidade.

Ninguém está interessado em ver o procedimento, o processo, é só resultado, aquilo ali tem que mostrar no final do ano para fechar o balanço. A educação virou balanço.

E não se vê a qualidade da avaliação (...) Se o professor ainda pensasse na avaliação, com referência [ao processo]. Isso não é um processo. Provavelmente é só para fazer...ou fingir.

Nos depoimentos acima percebe-se a presença das técnicas gerenciais adotadas nas escolas do município. Vale registro que os coordenadores pedagógicos são orientados a observar e monitorar o trabalho docente com base em uma matriz padronizada de formação na qual estão descritos, minuciosamente, indicadores e comportamentos esperados quanto ao planejamento curricular, gestão de sala de aula, práticas de ensino e de avaliação.

Observa-se também que professores e gestores percebem o quanto as pressões externas repercutem, negativamente, sobre o currículo e sobre a qualidade do trabalho escolar. Alguns até mesmo intuem que grande parte do esforço empreendido se reveste de um caráter performático que não necessariamente corresponde à qualidade de ensino do ponto de vista dos alunos.

Em experiências que eu tive [com atividades diferenciadas], os alunos que davam mais trabalho, assim, de comportamento ou interesse, foram aqueles que tiveram mais...não sucesso, mas os que mais participaram, porque fugia justamente do padrão que a gente segue no cotidiano.

Eu fiz um projeto [sobre mitos gregos]e ouvi: "ah! Mas [isso] não está na realidade do aluno. Mas o que é que tem? Ele vai gostar, é uma coisa muito prazerosa pra ele saber. Por mais que ele não vai [usar] na profissão, ele vai lembrar como uma coisa muito prazerosa de quando ele passou na escola.

Quando o professor tenta contextualizar [o conteúdo] e mostra a importância daquilo [...] o aluno adora, mas [o ensino] ainda é muito engessado, tem muito [de] decoreba"

E aí [o aluno] fala também: 'O que eu tô aprendendo é inútil'. Para o professor, ele acha que tudo que tem no currículo dele é útil, mas não é. 
Críticas e reflexões como essas não são enunciadas abertamente dentro das escolas. Primeiro, pela falta de tempo: “não dá tempo, nunca dá”. E também porque professores e coordenadores muitas vezes se calam, por medo. Na escola onde os participantes do estudo de Campos (2018) discutiram o tema da Educação em Direitos Humanos, uma Coordenadora Pedagógica admitiu: “A gente se omite!” “Tem professores que não falam as coisas porque acham que serão punidos. Estamos nesse ponto, do professor não poder falar".

O conservadorismo cultural, principalmente relacionado a pautas de costumes, também inibe a abordagem de "certos assuntos" dentro da escola, como apontou uma orientadora educacional: "A gente não pode falar de sexo, não pode falar de religião, não pode falar de política”. Como "clientes privilegiados”, algumas famílias, segundo depoimentos dos participantes, sentem-se no direito de impor restrições ao currículo, às quais a escola muitas vezes se “adapta”. Possivelmente porque, em São Caetano do Sul, todo mundo se conhece.

[Eu pedi] para pesquisarem sobre o Carnaval, mas teve uma carga na agenda dizendo que ela [determinada aluna] não ia pesquisar, porque não tinha a ver com a religião dela. O que é que a escola fez? 'Dá outro trabalho para ela!'

Eu gostei muito dessa lei que obriga entre aspas as escolas trabalharem com a cultura afro e indígena, porque [...] tem pai e mãe que não aceitam a cultura afro [por causa da religião]. Eles [alunos] não precisam acreditar naquela religião, eles precisam saber como é que funciona.

É a nossa função, sim, ser crítico, ensinar os nossos alunos a serem críticos, para construir uma sociedade melhor. Mas na base, a gente já é tolhido. [...] Tem retaliação sim, tem perseguição, sim.

Visões de senso comum com viés conservador também foram identificadas entre os professores. Ao serem indagados sobre o que lhes vinha à cabeça quando o assunto são direitos humanos, associações como estas apareceram:

Nossa! Eu penso em cadeias! Tropa de Elite! Que pena que nós que trabalhamos com as regras não temos direitos (risos) e quem não trabalha com as regras, tem .

[Eles] criaram os direitos humanos para conseguir incluir aqueles que a gente não incluiria, o assaltante, a pessoa que roubou.

Relação direito e dever. A própria escola, a gestão da escola, já indica que você tem que garantir o direito do aluno. Você não está ali para cobrar o dever dele.

O espírito competitivo é também marcante nas escolas do município. A disputa pelo melhor IDEB entre as cidades do ABC não apenas pauta o currículo como parece contaminar a relação das famílias com a escola e dos alunos e professores entre si. Essa questão foi enfatizada pelas professoras coordenadoras de área na escola onde Padovan (2018) conduziu reflexões sobre o sentido da educação integral. Integral é o que? indagouse uma delas, em meio a uma discussão sobre a finalidade da escola de tempo integral. 
A gente vai fazer o que o mercado pede, mas a gente não pode fazer só isso! Ele [aluno] precisa competir e ser solidário na competição. Não adianta nada eu ganhar sozinho. Que eu sozinho não sou nada.

E assim, o IDEB, nada melhor do que você chegar para o seu aluno: 'Viu? Nós fomos a melhor escola. [...] Então você também tem que ser o melhor lá fora.' Mas [na minha sala] os melhores, os destaques, se juntam para ajudar os outros que estão com problema.

O que me choca é que tem vários professores de matemática que focam muito no IDEB e que só querem os melhores alunos.

As ambivalências e paradoxos que o tema suscita ficam evidentes nessas falas. Também salta aos olhos o quanto a tomada consciência das contradições vividas por esses profissionais é geradora de mal-estar. Isso porque a escola fica sempre a meio caminho entre os ideais democráticos e de igualdade de direitos que sustentam os discursos de educação e os valores meritocráticos que, efetivamente, orientam as suas práticas.

Em meio às turbulências do dia a dia, professores e gestores perdem o senso de prioridade. O excesso de tarefas e o sentimento de dívida permanente transparecem na percepção de um tempo comprimido e fragmentado, como ilustram os comentários das coordenadoras de área que participaram do estudo de Umemura (2018).

Eu tenho a impressão que a gente não se aprofunda em nada porque [a gente] nem consegue dizer o que é mais importante.

Pois a gente faz de tudo um pouco; a gente olha as atividades que os professores mandaram, em época de prova, olha as provas, tem a parte de separar algum material que o professor pediu (...) e, muitas vezes, a gente tá na sala de aula para substituir professores que faltam.

São tantas questões burocráticas, são tantas coisas pra falar, acontecem tantas coisas numa escola, que fica quase impossível ter profundidade, a coisa ter o peso que ela merece.

Às vezes a gente marca: 'vou assistir sua aula'. [Mas] aí passa e você não assiste, porque é semana de prova, você tem que olhar a prova, e a cabeça vai ficando...E aí vem caso de indisciplina, que a gente vê muitos!

A rotina de trabalho das coordenadoras passa longe das atribuições pedagógicas do cargo previstas no Regimento Escolar, documento que, aliás, admitiram desconhecer. No primeiro contato que tiveram com esse documento, mostraram-se surpresas:

[...] mas isso é muito difícil de fazer de forma controlada! Acaba ficando muito ruim falar alguma coisa. A gente dá uma opinião, fala que vai procurar [o professor]. Mas sentar mesmo, se reunir, propor um texto para discutir...[isso] a gente não consegue fazer... 
Vale mencionar que o Regimento Escolar, que em tese deveria expressar os valores e concepções do projeto político pedagógico (PPP) de cada unidade de ensino, em SCS, é um documento único para todas as escolas exarado pela Secretaria de Educação. Nas três unidades pesquisadas esses documentos eram pouco ou totalmente desconhecidos, o que dá uma medida do grau de centralização e do quão pouco democráticas são as relações nessa rede de ensino. "Vocês conhecem o conselho de escola?" - indagou uma das pesquisadoras. Troca de olhares e risos preencheram o silêncio, dando pistas de que esse fórum de decisões colegiadas cumpre função meramente formal e burocrática (UMEMURA, 2018, p. 188).

Situação semelhante foi identificada em outra escola em relação ao PPP: “Também a gente não tem... Já pedi para deixar em cima da mesa dos professores, [mas] fica dentro da sala fechada, de uma gaveta fechada" (CAMPOS, 2018, p.177). O estudo conduzido por Padovan (2018, p. 158) confirmou que a participação e o trabalho coletivo não são pontos fortes dessa rede de ensino. Uma das demandas mais enfatizadas pelos participantes foi que tivessem "momentos em que os professores se percebam como grupo [e] que o trabalho seja feito em grupo".

Os estudos realizados nas escolas de SCS evidenciaram que apesar de críticos em relação às pressões externas, professores e gestores desconhecem a origem e, portanto, não questionam a intencionalidade das políticas a que estão submetidos. De certo modo, elas foram naturalizadas porque incorporadas à rotina das escolas. Daí que, ao serem convidados a sugerir práticas alternativas, emergiram, coladas ao seu vocabulário, propostas muito semelhantes às aprendidas nos cursos de capacitação oferecidos pelos "parceiros" da Secretaria de Educação ${ }^{7}$. Sinais da adesão (in)voluntária a esses discursos foram captados por Umemura (2018, p. 132-134).

Acho que deveríamos estabelecer metas por etapas, assim: 'até tal dia, tem que fazer tal coisa; 'tem que ler tal capítulo até tal data', porque [se não] vai chegando perto e não deu tempo, e vai fazendo na correria, e não chega com a qualidade que deveria.

Eu acho que na escola tudo deveria ser sistematizado; tudo teria que ter como funciona, com quem você fala; com quem pega os materiais.

Eu acho que poderíamos montar um banco de boas ideias, pra facilitar o nosso trabalho. Porque nem sempre a gente vai lembrar de tudo.

$E u$ acho que os professores poderiam assistir as aulas entre si [para] eles se ajudarem, avaliarem (...)não sei se essa observação tem que ser feita por um coordenador.

Com base no material empírico coletado, é plausível dizer que a "gestão do inconsciente” (HELOANI, 2018) em operação nessa rede de ensino tem sido relativamente exitosa. A assimilação do vocabulário tipicamente empresarial aos discursos pedagógicos (metas, prazos, banco de boas idéias) é a evidência mais aparente da identificação desses profissionais com a lógica gerencialista que organiza o currículo e as relações entre pares na escola. Com efeito, é no plano das representações (significações) sobre o lugar ocupado 
por eles na nova configuração do trabalho escolar que se confirma na adesão ao pacto proposto pela NGP: ao assumirem a posição de meros executores do projeto que lhes é dado como incumbência, posicionam-se subjetivamente como seus fiadores.

Em ambiente tão diretivo e tão pouco propício à escuta e ao diálogo não fazem uso da autonomia que lhes é "concedida" como contrapartida às responsabilidades a eles atribuídas. Nesse sentido, a autorregulação pressuposta nos mecanismos de controle da NGP não se realiza de modo pleno, pois embora se empenhem em cumprir metas, seguindo as orientações padronizadas com vistas à obtenção dos melhores scores nas avaliações de larga escala, o fazem por obediência, não porque "vestem a camiseta" do projeto. Contudo, o desconforto em relação ao modus operandi do modelo gerencial não se converte em críticas explícitas a ele, mas insinua-se em posicionamentos ambivalentes que, a um só tempo, escondem e revelam o temor de serem punidos por superiores hierárquicos.

Conclui-se, assim, que a economia que regula o trabalho escolar é perpassada pelas tensões entre excessos e faltas, cujo balanço é desfavorável à construção de relações democráticas na escola. Mergulhados e absorvidos pela avalanche de tarefas e urgências diárias de toda a sorte, pelo excesso de controle burocrático, pelas demandas por resultados e sob o olhar vigilante dos órgãos centrais de ensino, das famílias, dos alunos, e até mesmo de seus pares, professores e gestores descuidam do que de fato é importante. Porque lhes falta tempo, espaços de diálogo, de troca e escuta; mas, principalmente porque a competição imperante fragiliza os laços de solidariedade e confiança indispensáveis às identificações coletivas em torno de objetivos comuns.

Objetiva e subjetivamente, o resultado dessa equação é em grande parte atravessado pelo medo, pela perda do senso de prioridade, pela superficialidade e dispersão no tratamento do currículo; mas também pelo incentivo à corrosão do caráter e pela perda dos vínculos dos trabalhadores da educação com o processo e com o produto de seu trabalho. Em tais condições, a qualidade do ensino, em nome da qual restringe-se a autonomia das escolas e pela qual tantos esforços são empreendidos, serve para alimentar as ilusões dos estrategistas das políticas regulatórias e nutrir os interesses privados dos reformadores da educação (FREITAS, 2014).

Enquanto isso, enredado em tantas armadilhas, o projeto democrático dos educadores brasileiros, proferido em 1986, por Luiz Antônio Cunha na IV Conferência Brasileira de Educação, em Goiânia, permanece inconcluso em meio aos entraves que dificultam a sua realização. Ainda que avanços tenham sido feitos ao longo das últimas três décadas, os rumos da educação e do ensino continuam reféns de "castas burocráticas” e das "oscilações dos administradores do momento” (CUNHA, 1987).

Atualmente, uma outra onda de conservadorismo e obscurantismo, carregada de ameaças à democracia arduamente conquistada na Constituição Federal de 1988, paira sobre o país e sobre a educação brasileira. Com ela, novos obstáculos desafiam a resistência dos educadores. Enfrentar as intempéries desses tempos sombrios implica disposição política para lutar pelo estado democrático de direito, o que pressupõe desconstruir, subjetivamente, representações que associam o poder público a um "pai severo" (SCHWARCKS, 2019) ou a uma “mãe protetora” (HELOANI, 2018). 


\section{Considerações Finais}

Neste texto procurei identificar elementos que auxiliassem a compreensão de por que o princípio da gestão democrática da educação parece ser um projeto tão difícil de ser concretizado. Para tanto, busquei articular postulados do modelo gerencial adotado pela Nova Gestão Pública, hoje hegemônico, com os traços autoritários e conservadores da herança histórica e cultural da sociedade brasileira em sua relação com o Estado e com os poderes públicos.

Argumentei que os efeitos produzidos pelas políticas regulatórias de educação, especialmente as que têm como foco o binômio avaliação-currículo, na organização da escola e na formação das subjetividades docentes se apresentam como epifenômeno do espírito concorrencial implementado pela Nova Gestão Pública (NGP), na esteira das mudanças do papel do Estado requeridas pela globalização da economia.

Na medida em que expressões como "eficiência" e "eficácia" (dos processos) ou foco nas "metas" (e resultados) foram incorporadas ao vocabulário da educação, o universo de representações de professores e gestores foi sendo embalado por fórmulas meritocráticas de gestão, pelas promessas de recompensa e pelas ameaças de sanções que acompanham esses discursos. Com essas estratégias, pretensamente racionais e politicamente neutras, o espírito da NGP procurou forjar, entre os servidores públicos, novos modos de pensar (e agir) conformados - ajustados à forma e ao conteúdo - à visão de mundo, aos valores e às práticas de trabalho do setor privado.

Com efeito, a assimilação do modelo gerencial de administração pública se mesclou à tradição conservadora e autoritária da sociedade brasileira, conferindo-lhe traços muito peculiares. O processo de abertura política, iniciado na década de 1980, embora tenha logrado avanços na direção de conquistas democráticas, foi mais um hiato entre períodos de autoritarismo recorrentes na história brasileira, como hoje se constata com a ascensão ao poder de mais um títere das forças ultraconservadoras deste país.

Nesse sentido, o esforço empreendido ainda não foi suficiente para banir das práticas sociais os seus traços de origem. Até mesmo os governos que pretenderam promover uma reforma do Estado por meio de políticas liberalizantes não conseguiram sobrepor-se totalmente a essa herança cultural. Frente aos conhecidos obstáculos, o neoliberalismo à brasileira preferiu associar-se às forças mais conservadoras e autoritárias de nossa sociedade.

O peso dessa história, viva no tecido social brasileiro, se faz presente nas relações escolares atravessadas pelo medo e pela desconfiança. A combinação dessas marcas subjetivas com o espírito competitivo instaurado pelos mecanismos gerenciais de controle e poder tende a enfraquecer ainda mais os laços sociais e a potencializar os históricos entraves à construção de relações democráticas na escola pública.

A pesquisa que inspirou essas reflexões sinalizou que o enfrentamento desses entraves não é tarefa simples, pressupõe a desconstrução dos discursos hegemônicos que se hibridizam nas práticas cotidianas das escolas. Não obstante, em meio ao mal-estar gerado 
pelas contradições que emergem nesse processo e à memória de conquistas democráticas duramente alcançadas pelos educadores nas últimas décadas, vislumbram-se possibilidades de resistência. Entende-se que a consideração desses elementos nas pesquisas curriculares pode contribuir para a ampliação do entendimento dos desafios deste campo frente à nova onda de conservadorismo que paira sobre a educação brasileira.

\section{Notas}

1. O Plano Diretor refere-se à ideologia do Estado Mínimo como uma resposta inadequada do modelo neoliberal à crise do Estado da segunda metade dos anos 80, propondo como alternativa "a reconstrução do Estado (brasileiro), "de forma a resgatar sua autonomia financeira e sua capacidade de implementar políticas públicas” (BRASIL, 1995, p. 11).

2. Alusão à expressão cunhada por Étienne de La Boétie em seu Discurso da Servidão Voluntária. O manuscrito, considerado um hino à liberdade, foi entregue pelo autor ao seu amigo e filósofo, Michel de Montaigne (1533-1592), pouco antes de morrer, em 1563. Cf. o tradutor Laymert Garcia dos Santos, 1982.

3. Desde sua primeira eleição, a Prefeitura de SCS tem sido administrada por partidos de direita ou centro-direita: de 1949-1953, pelo PSP (de Ademar de Barros); de 1954-1957, pela UDN; de 1965 a 1982 revezaram-se candidatos da ARENA e do MDB; de 1982 até 2012, pelo PTB; de 2013-2016, pelo PMDB; o atual prefeito foi eleito pelo PSDB, mas já administrou a cidade pelo PTB de 2008 a 2012. Fonte: http://www.tribunadoabcd.com.br/onze-homens-foramprefeitos-de-sao-caetano-do-sul-em-seus-69-anos-de-emancipacao-politico-administrativa/

4. A rede atualmente conta com 7 escolas de tempo integral e 3 de Ensino Fundamental e Médio. Conta, ainda, com 16 Escolas Municipais Integradas (EMIs) de Educação Infantil em período integral; 22 Escolas de Educação Infantil (EMEIs) e três creches conveniadas. Fonte: http://www.saocaetanodosul.sp.gov.br/secretarias/educacao.html

5. O Ideb 2017 nos anos iniciais superou a meta $(6,8)$, cresceu e alcançou 7,5; nos anos finais, superou a meta $(5,8)$ cresceu e alcançou 6,2.

6. Os profissionais envolvidos são professoras e coordenadoras pedagógicas de escolas de Ensino Fundamental da rede de SCS que, à época (2016-2018), desenvolviam pesquisas no Mestrado Profissional em Educação da Universidade Municipal de São Caetano do Sul - USCS.

7. Em 2013, a Seduc de SCS firmou parceria de 18 meses com a Fundação Lemann (Programa Técnicas Didáticas. Disponível em: https://www.abcdoabc.com.br/sao-caetano/noticia/sao-caetano-assina-parceria-educacional-fundacaolemann-9207; Em 2015, com o Itaú Social (Programa Tutoria), ambos com o objetivo de capacitar os gestores e “aumentar a efetividade do trabalho dos gestores escolares na Educação Infantil e Ensinos Fundamental e Médio". Disponível em: https://www.abcdoabc.com.br/sao-caetano/noticia/educacao-sao-caetano-celebra-resultadosprograma-tutoria-44448

\section{Referências}

ADRIÃO, Theresa; GARCIA, Teise; BORGHI, Raquel, ARELARO, Lisete. As parcerias entre prefeituras paulistas e o setor privado na política educacional: expressão de simbiose?. Educação \& Sociedade (Impresso), v. 33, p. 533-549, 2012.

ADRIÃO, Theresa M. de Freitas. Dimensões e formas da privatização da educação no Brasil: caracterização a partir de mapeamento de produções nacionais e internacionais. Currículo sem Fronteiras, v. 18, n. 1, p. 828, jan./abr. 2018. Disponível em: http://www.curriculosemfronteiras.org/vol18iss1articles/adriao.pdf Acesso em: 13 ago. 2019.

ANDERSON, Gary. Privatizando subjetividades: como a Nova Gestão Pública está criando um "novo” profissional da educação. RBPAE - Revista Brasileira de Política e Administração na Educação [impresso] v.33, n. 3, p. 593-626. 
ARROYO, Miguel G. Administração da educação, poder e participação. Educação e sociedade, v. 1, n. 2, p. 36-46, 1979.

ARROYO, Miguel G. Ofício de Mestre: imagens e auto-imagens. 11ª. ed. Petrópolis, RJ: Vozes, 2009. 251p.

AVELAR, Marina; BALL, Stephn J. Mapping new philanthropy and the heterarchichal state: The Mobilization for the National Learning Standards in Brazil. International Journal of Education Development, v. 64, p. 65-73, Jan. 2019.

Disponível em: https://www.sciencedirect.com/science/article/pii/S0738059317302080?via\%3Dihub. Acesso em: 25 ago. 2019.

BALL, Stephen J. Profissionalismo, gerencialismo e performatividade. Cadernos de Pesquisa., São Paulo, v. 35, n. 126, p. 539-564, Dez. 2005.

Disponível em: http://www.scielo.br/scielo.php?script=sci_arttext\&pid=S010015742005000300002\&lng=en\&nrm=iso . Acesso em: 25 ago. 2019.

BALL, Stephen J. Education plc. Understanding private sector participation in public sector education. London/New York: Routledge, 2007. 216p.

BALL, Stephen J.; MAGUIRE, Meg; BRAUN, Annette. How schools do policy. Policy enactments in secondary schools. London, USA, Canada: Routledge, 2012. 173p.

BONAMINO, Alicia; SOUSA, Sandra Zákia. Três gerações de avaliação da educação básica no Brasil: interfaces com o currículo da/na escola. Educação e Pesquisa, v. 38, n. 2, p. 373-388, 2012. Disponível em: http://www.scielo.br/pdf/ep/v38n2/aopep633.pdf Acesso em: 23 ago. 2019.

BRASIL [Presidência da República]. Plano Diretor da Reforma do Aparelho do Estado. Brasília, 1995. Disponível em: http://www.bresserpereira.org.br/documents/mare/planodiretor/planodiretor.pdf Acesso em: 10 ago. 2019.

CAMPOS, Géssica Natália. Educação em Direitos Humanos: reflexões com uma escola da rede municipal de São Caetano do Sul. 2018. 207f. Dissertação [Mestrado Profissional em Educação]. Universidade Municipal de São Caetano do Sul, São Caetano do Sul.

CHAUÍ, Marilena. Sobre o direito à preguiça. In: NOVAES, Adauto (Org.). Mutações: elogio à preguiça. São Paulo: Edições Sesc/SP, 2012. p. 77-105.

CHIRINÉA, Andréa Melanda; BRANDÃO, Carlos da Fonseca. O IDEB como política de regulação do Estado e legitimação da qualidade: em busca de significados. Ensaio: aval. pol. públ. Educ., Rio de Janeiro, v. 23, n. 87, p. 461-484, abr./jun. 2015. Disponível em: $<$ http://www.scielo.br/pdf/ensaio/v23n87/0104-4036-ensaio-23-87- 461.pdf>. Acesso em 01 de agosto de 2019.

CUNHA, Luís Antônio. A Educação na Nova Constituição. Revista da Associação Nacional de Educação ANDE, Ano 6, n. 12, 1987.

CURY, Carlos Roberto Jamil. Gestão democrática da educação: exigências e desafios. Revista Brasileira de Política e Administração da Educação, v.2, n.18, jul./dez. 2002. Disponível em: https://seer.ufrgs.br/rbpae/article/view/25486/14810 Acesso em: 05 ago. 2019.

DOURADO, Luiz Fernandes. A escolha dos dirigentes escolares: políticas e gestão da educação no Brasil. In: FERREIRA, N. S. C. Gestão democrática da Educação: atuais tendências, novos desafios. São Paulo: Cortez, 2001. p.95-117.

DRABACH, Neila Pedrotti. As formas de provimento à função de diretor escolar no Brasil a partir da reforma do estado de 1995. In: Simpósio Brasileiro de Política e Administração da Educação, 26, 2013, Recife. Anais. $\quad$ Recife: $2013 . \quad$ ANPAE, Disponível em: http://www.anpae.org.br/simposio26/1comunicacoes/NadiaPedrotttiDrabach-ComunicacaoOral-int.pdf. Acesso em: 10 ago. 2019. 
DRABACH, Neila Pedrotti. A trajetória de construção do princípio da gestão democrática na legislação educacional brasileira. $R$. Transmutare, Curitiba, v. 1, n. 2, p. 275-292, jul./dez. 2016. Disponível em: https://periodicos.utfpr.edu.br/rtr/article/view/4594/3436 Acesso em: 20 ago. 2019

DUBAR, Claude A crise das identidades: a interpretação de uma mutação. Porto: Edições Afrontamento, 2006. 206 p.

DUBAR, Claude. A construção de si pela atividade de trabalho: a socialização profissional. Trad. Fernanda Machado. Cadernos de Pesquisa, v. 42 n. 146-367, maio/ago. 2012. Disponível em: http://www.scielo.br/pdf/cp/v42n146/03.pdf. Acesso em: 16 ago. 2019.

DUPAS, Gilberto. Tensões contemporâneas entre o público e o privado. São Paulo: Paz e Terra, 2003. 145p.

FÉLIX, M. de F. Administração escolar: um problema educativo ou empresarial? São Paulo: Cortez/Autores Associados, 1984.

FREITAS, Luiz Carlos de. Os Reformadores Empresariais da Educação e a disputa pelo controle do processo pedagógico na Escola. Educação e Sociedade, Campinas, v. 35, n. 129, p. 1085-1114, 2014. Disponível em: http://www.scielo.br/pdf/es/v35n129/0101-7330-es-35-129-01085.pdf Acesso em: 14 ago. 2019

FUNDAÇÃO SEADE. Fundação Sistema Estadual de Análise de Dados. Portal de Estatísticas do Estado de São Paulo. Disponível em: <https://www.seade.gov.br>

GANDINI, R.P.C.; RISCAL, S.A. A gestão da educação como setor público não-estatal e a transição para o estado fiscal no Brasil. In: OLIVEIRA, D.A.; ROSAR, M.F.F. (Org.). Política e Gestão da Educação. 2ª . ed. Belo Horizonte: Autêntica, 2008. p.41-50.

GARCIA, Paulo Sérgio et at. Formação, atuação e formas de gestão dos diretores de escola da Região do ABC. In: GARCIA, Paulo Sérgio; PREARO, Leandro. (Org.) Avaliação da educação escolar no Grande ABC Paulista: primeiras aproximações. São Paulo, Plêiade, 2015. 181p.

HELOANI, Roberto. Modelos de Gestão e Educação: gerencialismo e subjetividade. São Paulo: Cortez, 2018. 238p.

IBIAPINA, Ivana Maria Lopes de Melo. Pesquisa colaborativa: investigação, formação e produção de conhecimentos. Brasília, Líber Livro, 2008.

LIMA, C. L. A escola como organização educativa: uma abordagem sociológica. São Paulo: Cortez, 2001.189p.

LIMA, Iana Gomes de; GANDIN, Luís Armando. Gerencialismo e dispersão de poder na relação Estadoeducação: as traduções e os hibridismos do caso brasileiro. RBPAE - Revista Brasileira de Política e Administração na Educação [impresso] v.33, n. 3, p.729-749.

MARTINS, José de Souza. Subúrbio. Vida cotidiana e história no subúrbio da cidade de São Paulo: São Caetano, do fim do Império ao fim da República. 2a . ed. São Paulo: Hucitec/Unesp, 2002. 365p.

MARTINS, A. M.; MACHADO, C.; BRAVO, M. H. Trajetórias de formação e profissionais dos diretores de escolas municipais: respostas declaradas ao questionário contextual da Prova Brasil (2015). Jornal de Políticas Educacionais, v. 12, n. 13, p.1-17, jul., 2018. Disponível em https://revistas.ufpr.br/jpe/article/view/58910/35724. Acesso em: 08 jun. 2019.

MENDONCA, Erasto Fortes. Estado patrimonial e gestão democrática do ensino público no Brasil. Educ. Soc., Campinas, v. 22, n. 75, p. 84-108, Aug. 2001. Disponível em: http://www.scielo.br/pdf/es/v22n75/22n75a07.pdf Acesso em: 22 ago. 2019.

PADOVAN, Maria Isabel. Educação integral e gestão democrática: contribuições da coordenação pedagógica de uma escola de São Caetano do Sul. 2018. 160f. Dissertação [Mestrado Profissional em Educação] Universidade Municipal de São Caetano do Sul, São Caetano do Sul.

PARO, Vitor Henrique. Gestão democrática da escola pública. São Paulo: Ática, 2016. 134p. 
PERONI, Vera Maria Vidal. Múltiplas formas de materialização do privado na educação básica pública no Brasil: sujeitos e conteúdo da proposta. Currículo sem Fronteiras, v. 18, n. 1. P. 212-238, jan./abr.2018 Disponível em: http://www.curriculosemfronteiras.org/vol18iss1articles/peroni.pdf Acesso em: 13 ago. 2019.

PONCE, Branca Jurema. O Tempo no Mundo Contemporâneo: o tempo escolar e a justiça curricular. Educ. Real., Porto Alegre, v. 41, n. 4, p. 1141-1160, dez. 2016. Disponível em: http://www.scielo.br/pdf/edreal/v41n4/2175-6236-edreal-60533.pdf Acesso em: 03 set. 2019.

ROSA, Sanny S. da.; CAMPOS, Gessica Natalia; PADOVAN, Maria Isabel; UMEMURA, Vanessa M.V. Gestão Pedagógica e Qualidade social da educação: contribuições da pesquisa colaborativa em escolas de São Caetano do Sul. Revista e-Curriculum, São Paulo, v.16, n.4, out/dez. 2018. Disponível em: https://revistas.pucsp.br/curriculum/article/view/36398/27953 Acesso em: 03.09.2019.

ROSA, Sanny S. da. Reformas Educacionais e Pesquisa: As políticas “em cena” no Brasil e na Inglaterra. Revista e-Curriculum, São Paulo, v. 8 n. 2, ago. 2012. Disponível em: https://revistas.pucsp.br/curriculum/article/view/10840 . Acesso em: 03.09.2019.

SANTOS, Laymert Garcia dos. [Trad.] Discurso da Servidão Voluntária - Etienne de La Boétie. 2a . ed. São Paulo, Brasiliense, 1982. 239p.

SENNET, Richard. A corrosão do caráter: consequências pessoais do trabalho no novo capitalismo. Rio de Janeiro: Record, 1999. 204p.

SCHWARCZ, Lilia Moritz. Sobre o autoritarismo brasileiro. 1ª ed. São Paulo: Companhia das Letras, 2019. 273p.

UMEMURA, Vanessa M. Vicente. Coordenação pedagógica e a qualidade social da educação: um estudo baseado na pesquisa-ação colaborativa. 2018. 210f. Dissertação [Mestrado Profissional em Educação]. Universidade Municipal de São Caetano do Sul, São Caetano do Sul.

\section{Correspondência}

Sanny Silva da Rosa: Doutora em Educação (Currículo) pela PUC-SP; estudos de pós-doutoramento no Institute of Education (IOE), University of London; professora e pesquisadora do Programa de Pósgraduação Stricto Sensu em Educação da Universidade Municipal de São Caetano do Sul (USCS). Linha de Pesquisa: Políticas e Gestão Educacional.

E-mail: sanny.rosa@prof.uscs.edu.br

Texto publicado em Currículo sem Fronteiras com autorização da autora 